\title{
Using poetry to explore difficult issues in children's nursing
}

\section{Context}

Nursing is a stressful occupation, a fact that is evidenced by the high incidence of mental health issues reported by nursing staff (National NHS Staff Survey Coordination Centre, 2013). Children's nursing can be heart breaking, as there is often no explanation for the infant, child or young person becoming critically ill or being lost to an early death. Nurses are required to be caring and compassionate, although recent reports have highlighted concerns about the ability of nurses to relate to others, and this has led to initiatives to reinforce the need for compassionate action (Cummings and Bennett, 2012). Child branch student nurses can struggle with compassionate and empathetic care provision to parents. This does not necessarily arise from a deliberate lack of care for others, a claim sometimes made by the media (Dean, 2014), but more from an inability to see parent's perspectives, particularly in the challenging area of the Neonatal Intensive Care Unit (NICU).

Neonatal nursing is a specialist area which requires the delivery of often crisis focused highly technical care to extremely premature and fragile infants (Vittner, 2009). This may involve ethical decision making and moral reasoning surrounding withdrawal of treatment, as well as the emotional care of vulnerable and initially powerless infants and family members. Aagaard and Hall (2008) discuss the needs of families on the NICU and describe the stress, alienation, uncertainty and grieving process which take places for the loss of a healthy full term infant. They also detail 
how traumatic dealing with the infant's appearance, fragility and reliance on invasive treatments and complicated equipment can be. For student nurses, these aspects can also be terrifying and disturbing. Downey et al (1995) and Yam et al (2001) found nurses in NICU experienced intense sorrow and a feeling of helplessness on the death of a baby as well as insecurity about their knowledge and ability to help grieving families.

Rice (1999) articulates some of the difficulties in nursing: the effort, the giving, and personal sacrifice require introspection and the ability to step outside of ourselves in order to truly master the art of caring needed to be a really good nurse. In order to understand the complex and ambiguous situations experienced, a different knowledge base may be needed (DeBrew, 2010). A liberal approach to learning is one that encourages and develops creative thinking. Liberal education (including the use of literature, poetry and the visual arts) has been linked with an array of rewards for students, including academic, personal and professional growth (DeBrew, 2010). Jensen and Curtis (2008) suggest that a liberal education can support the development of self-awareness, self-understanding and empathy. For example, activities such as poetry writing can help us relate to others on a different level, understanding the person rather than the illness (Davis, 1997). Mohammadian et al (2011) suggest that reading and discussing poetry has a positive effect on selfesteem and self-exploration, and can reduce anxiety and stress. Many nurses and health care professionals have used poetry to communicate their own personal and professional journey and document their feelings, thoughts and needs (Charon, 2008; Tilley-Lubbs, 2011; McKie, 2012). An advantage for educators is that liberal approaches provide an opportunity to utilise alternative pedagogical practices. These 
can help to challenge some of the dominant and more negative current curricular features, including generality, impersonality and the predictability of practices such as reading from 'power point' slides, which can induce student boredom and demotivation (Milligan and Woodley, 2010).

\section{The Innovation}

The aim of the innovation was to explore the use of poetry for child branch student nurses at the commencement of their third year critical care module. The innovation particularly focussed on neonatal death and parental bereavement, as students were apprehensive and fearful about these aspects of NICU practice in comparison to other areas. The poems chosen were written by parents who had experienced NICU and were available for public viewing online:

(http://www.oocities.org/haley25wks/TPP/poems.html)

1) 'As I Love You Through The Glass' by Elena Murphy (describes a mother's experience of the NICU environment)

2) 'Into Your Hands' by Alan Van Orman (describes the responsibility of the NICU nurse)

3) 'Dark Empty Pit' by Lynette Marie Stokes (describes a mothers suffering following neonatal bereavement)

The cohort of 32 students was split into three groups. Each group was asked to read one of the three poems and then reflect on their feelings and thoughts. The safety of the students was paramount throughout this exercise. The nature of the poems was 
discussed with the students beforehand, and the facilitator was experienced in debriefing clinical staff following hospital emergencies, so was well placed to provide support to the students if required, for example, if they became distressed by the content of the poems or subsequent discussion.

\section{Initial Evaluation}

Using poetry to reflect on practice issues has been shown to be beneficial, particularly when attempting to understand our own and others' experiences (Jack, 2015). This can enhance both intra and interpersonal development. Hahessy (2015: 3) suggests that engaging with poetry can confirm the 'relational connection' and support engagement with others as humans rather than 'patients'. Therefore, on examination of the findings, it was important to understand the extent to which the poems had supported the recognition of others' feelings and experiences, and this informed the areas chosen for evaluation.

Students were asked how they felt about the topics of neonatal death and parental bereavement prior to the educational experience. They discussed the apprehension parents may have of neonatal equipment and the need for the nurse to explain things clearly. When reflecting on bereavement, the students showed high levels of anxiety and felt uncertain about what they might be required to do or say.

Students commented particularly on the poem 'Dark Empty Pit', a piece which explores neonatal death and bereavement. They suggested that engaging with this poem supported development of a more family centred, compassionate approach 
that would be helpful to them in practice. Typical comments included: 'Really interesting exercise and gained knowledge from a parent's perspective'; 'This was helpful and encouraged me to think more about effects on the parents'. Students also commented on their own sadness for the family involved in the poem, and acknowledged their inability to fully relate or empathise with something so complex. They also stated that the poem helped them to see things differently and gave them a deeper insight into the difficulties a neonatal death brings for health professionals and parents. Student comments included: 'makes you explore in a different way, makes you dig deeper as the poem could have meant different things'; 'makes me feel empathy and how difficult it must be for them (parents) and the importance of support and family centred care'.

The students stated that the exercise had helped expose their concerns about particular aspects of practice such as the practical care of the dying, spirituality and health professional support in times of emotional distress. Having identified these aspects of practice, their discussion in future theory based sessions became more relevant. Three of the 32 students felt they had low levels of knowledge for the parents' situation following this exercise, and six felt unsure. The focus of this exercise was to support the development of the relational aspects of care giving rather than to increase the students' practical knowledge base. However, having identified a lack of knowledge among some students, future theory-based sessions could be tailored to meet students' needs. 


\section{Impact on Learning}

Most participants suggested that the exercise had developed their ability to see things from another's perspective, which is the core element of an empathetic approach. Providing these opportunities for creative learning might enable continuous development of interpersonal skills.

This exercise seemed to develop the students' self-awareness, a desirable attribute in nursing practice. It is only when we know ourselves and become aware of our own strengths and limitations that we can begin to know and accept others, and the students commented on their inability to relate to complex issues such as neonatal bereavement at this time. By being aware of this, the students can take steps to develop their learning and responses in this important aspect of practice.

The use of poems developed the students' ability to consider the emotional aspects of NICU nursing. In such a high intensity environment, there can be a focus on the more technical aspects of care and medical interventions. Taking time to read and understand poems places the focus on the emotions and develops emotional sensitivity towards the family and the self.

The students enjoyed a different style of learning, which engaged them in a different way compared to the usual more didactic approaches. The use of poems supports development of creativity; for example, through the use of metaphor, aspects can be revealed in different ways to the usual. Thinking creatively is helpful for learner development as it can support problem solving in the practice setting (Chan, 2012). Often, practice issues are not straightforward and nurses need to think creatively in order to solve complex problems. 
The findings from this initial work are promising although there are important practical aspects to consider when developing more creative and student centred approaches to education. It can be a challenge to nurse educators to provide the educational contexts which permit creative and imaginative learning for students to develop (Warne and McAndrew, 2010). Educators might already feel overstretched in their roles, and supporting learning at deeper and more meaningful levels might prove too challenging. Lillyman et al (2011) suggest that that educators need to incorporate their pastoral role into their classroom teaching in order to create the nurturing environment required and ensure that learning development takes place.

\section{Conclusion}

Coping with the NICU placement can be challenging for student nurses who struggle to cope with what they experience in this area. We suggest that using poetry to explore some of the issues relating to neonatal illness and death might be beneficial in terms developing empathy towards others and raising self-awareness. This is important, not only for the parents but for the students' psychological well-being in being able to cope, and come to terms with important and difficult issues. 


\section{References}

Aagaard, H. and Hall, E. O. C. (2008) Mothers' Experiences of Having a Preterm Infant in the Neonatal Care Unit: A Meta-Synthesis. Journal of Paediatric Nursing, 23, (3) pp 26-36.

Chan ZCY (2012) A systematic review of creative thinking/creativity in nursing education Nurse Education Today 33, (11) pp1382 - 7

Charon, R. (2008) Narrative medicine; Honouring the stories of illness. Oxford University Press, New York.

Cummings, J. \& Bennett, V. (2012) Compassion in Practice. www.commissioningboard.nhs.uk (last accessed 13.7.15)

Davis, C. (1997) Poetry about patients: Hearing the nurse's voice Journal of Medical Humanities 18, (2) pp. 111-125.

Dean, E. (2014) Lancet commission to tackle the poor perception of UK nursing. Nursing Standard 28, (21), p. 10

DeBrew, J. K. (2010) Perceptions of liberal education of two types of nursing graduates: the essentials of baccalaureate education for professional nursing practice. The Journal of General Education 59 (1) pp. 42-62. 
Downey, V. Bengiamin, M. Heuer, L. Juhl, N. (1995) Dying babies and associated stress in NICU nurses. Neonatal Network, 14, pp 41-46.

Hahessy S (2015) Reflections on the use of Poetry in Nurse Education: Speaking a Credible Language of Care Nurse education in Practice (In press) Jack K (2015) The use of poetry writing in nurse education: An evaluation 35, (9) pp7 $-10$

Jensen, A. \& Curtis, M. (2008) A descriptive qualitative study of student learning in a psychosocial nursing class infused with art, literature, music and film. International Journal of Nursing Education Scholarship 5 (1) pp. 1-9.

Lillyman, S. Gutteridge, R. \& Berridge, P. (2011) Using a storyboarding technique in the classroom to address end of life experiences in practice and engage students in deeper reflection Nurse Education in Practice 11, pp. 179 - 185.

McKie, A. (2012) Using the arts and humanities to promote a liberal nursing education: strengths and weaknesses. Nurse Education Today 32, pp. 803-810.

Milligan, E. \& Woodley, E. (2010) Creative, expressive encounters in health ethics education: ethics as relational engagement. In: Milligan, E. Woodley, E. (Eds) Confessions - Confounding Narrative and Ethics. Cambridge Scholars Publishing: Newcastle-upon-Tyne. 
Mohammadian, Y., Shahidi, S., Mahaki, B., Mahammadi, A.Z., Baghban, A.A. and Zayeri, F. (2011) Evaluating the use of poetry to reduce signs of depression, anxiety and stress in Iranian female students. The Arts in Psychotherapy. 38, pp. 59-63.

National NHS Staff Survey Co-ordination Centre (2013) Briefing note: Issues highlighted by the 2012 NHS staff survey in England http://NHS\%20staff\%20survey\%202012 nationalbriefing final.pdf (last accessed 13.7.15)

Tilley-Lubbs, G.A. (2011) The Coal Miner's Daughter gets a PHD. Qualitative Inquiry 17 (8) p720-722.

Vittner, D. (2009) Reflective strategies in the neonatal clinical area. Advanced Neonatal Care, 9 (1) pp43-45.

Warne, T. \& McAndrew, S. (2010) Creative Approaches to health and social care education. Palgrave MacMillan: Basingstoke.

Yam, B. M. C. Rossiter, J. C. Cheung, K. Y. S. (2001) Caring for dying infants: experiences of neonatal intensive care nurses in Hong Kong. Journal of Clinical Nursing, 10, pp 651-659. 